Tropical Journal of Pharmaceutical Research February 2019; 18 (2): 243-249

ISSN: $1596-5996$ (print); 1596-9827 (electronic)

(C) Pharmacotherapy Group, Faculty of Pharmacy, University of Benin, Benin City, 300001 Nigeria.

\title{
Formononetin promotes apoptosis of colorectal cancer cells via activation of mitochondria-dependent MAPK pathway
}

\author{
Xiao-hong Wang ${ }^{1}$, Zhi-guang Sun ${ }^{2 \star}$, Lei Luo ${ }^{3}$, Li-na Liu ${ }^{4}$, Jing Yan ${ }^{5}$, Li Xuan ${ }^{6}$ \\ ${ }^{1}$ Department of Gastroenterology, Xuzhou Affiliated Hospital of Nanjing University of Chinese Medicine, ${ }^{2}$ Department of \\ Headmaster's Office, Nanjing University of Chinese Medicine, ${ }^{3}$ Department of Gastroenterology, Second Affiliated Hospital of \\ Nanjing University of Chinese Medicine, ${ }^{4}$ Department of Hepatology, The Affiliated Hospital of Nanjing University of Chinese \\ Medicine, ${ }^{5}$ Department of Research and Experiment Center, First Clinical Medical College, Nanjing University of Chinese \\ Medicine, ${ }^{6}$ Department of Gastroenterology, Xuzhou Hospital of Traditional Chinese Medicine, Nanjing, China
}

*For correspondence: Email: ZhiguangSunasd@163.com

Sent for review: 7 November 2018

Revised accepted: 22 January 2019

\begin{abstract}
Purpose: To investigate whether formononetin exhibits antitumor activity in colorectal cancer cell lines via the mitochondria-dependent mitogen-activated protein kinase (MAPK) pathway.

Methods: Human colorectal cells were treated with various doses of formononetin for $24 h$, followed by Cell Counting Kit-8 (CCK-8) assay and western blot. Human colorectal cells were incubated with equivalent vehicle (DMSO) or $100 \mu \mathrm{M}$ formononetin for $24 \mathrm{~h}$, followed by nuclear staining with propidium iodide (PI) and diamidino-2-phenylindole (DAPI) for analyses of apoptosis. Human colorectal cells were incubated with equivalent vehicle or $100 \mu \mathrm{M}$ formononetin for $24 \mathrm{~h}$ followed by analysis of cell migration and invasion. Human colorectal cells were incubated with equivalent vehicle (DMSO) or $100 \mu \mathrm{M}$ formononetin for various duration $(3,6,12$, and $24 \mathrm{~h})$, followed by detection of intracellular reactive oxygen species (ROS) level and measurement of mitochondrial membrane potential $(\Delta \psi \mathrm{m})$ to monitor mitochondria functionality.

Results: In human colorectal cancer cell lines SW1463 and T84, formononetin (> $20 \mu \mathrm{M}$ ) significantly inhibited cell growth $(p<0.05)$ in a dose-dependent manner, noticeably induced apoptosis, and suppressed cell migration and invasion. Western blot analysis revealed that formononetin treatment caused significantly increased levels of proapoptotic proteins, and suppression of cell proliferationrelated protein and matrix metallopeptidases (MMP) levels. Formononetin also induced mitochondrial depolarization and ROS generation in a time-dependent manner, indicating that formononetin mediates human colorectal cancer cell apoptosis via activation of MAPK pathway in a dose-dependent manner.

Conclusion: Formononetin induces human colorectal cancer cell apoptosis via mitochondriadependent MAPK pathway, thus lending experimental support for the clinical application of formononetin for colorectal cancer therapy.
\end{abstract}

Keywords: Formononetin, Colorectal cancer, Mitochondria, Reactive oxygen species, Cytochrome C, Mitogen-activated protein kinase

\footnotetext{
This is an Open Access article that uses a funding model which does not charge readers or their institutions for access and distributed under the terms of the Creative Commons Attribution License (http://creativecommons.org/licenses/by/4.0) and the Budapest Open Access Initiative (http://www.budapestopenaccessinitiative.org/read), which permit unrestricted use, distribution, and reproduction in any medium, provided the original work is properly credited.

Tropical Journal of Pharmaceutical Research is indexed by Science Citation Index (SciSearch), Scopus, International Pharmaceutical Abstract, Chemical Abstracts, Embase, Index Copernicus, EBSCO, African Index Medicus, JournalSeek, Journal Citation Reports/Science Edition, Directory of Open Access Journals (DOAJ), African Journal Online, Bioline International, Open-J-Gate and Pharmacy Abstracts
} 


\section{INTRODUCTION}

Colorectal cancer (CRC) is the third most common cancer and the second leading cause of cancer-related death in the world [1]. Most patients with advanced CRC also have distant metastases [2]. Although the most common location of metastases from CRC is the liver, 2.1 $\%$ of CRC patients have lung metastases which often results in poor prognosis [3]. Adjuvant systemic chemotherapy is the main treatment for advanced CRC. However, side effects and the development of chemoresistance are common limitations [4]. Thus, it is imperative to develop alternative CRC chemotherapies with fewer adverse effects.

Formononetin is an O-methylated isoflavone and phytoestrogen and it is extracted from the roots of Astragalus membranaceus. Formononetin is a traditional Chinese herb and has been widely used as a popular herbal medicine for more than 2,000 years eliciting a variety of biological effects in many diseases [5]. Previous studies have shown that formononetin exhibits anticancer effects via the upregulation of the phosphatidylinositol 3-kinase/protein kinase B (PI3K/Akt) signalling pathway [6]. Formononetin has been also suggested to promote cellular apoptosis involving the mitogen-activated protein kinase (MAPK) pathway [7]. Mitochondrial reactive oxygen species (ROS), acting upstream of MAPK, initiates mitochondrial-dependent apoptosis [8]. The present study shows that formononetin can induce mitochondrial depolarization and dysfunction with increased intracellular ROS levels, which leads to the activation of MAPK pathway and the release of proapoptotic proteins (cytochrome $\mathrm{C}$ ) to promote cellular apoptosis.

\section{EXPERIMENTAL}

\section{Human cell lines and reagents}

Human colorectal adenocarcinoma cell line SW1463, human colonic adenocarcinoma cell line T84 (derived from lung metastases), and normal human intestinal epithelial cells (HIEC-6) were purchased from Chinese Academy of Sciences, Shanghai Institute of cell biology library. Foetal bovine serum (FBS), Leibovitz's 15 medium, Ham's F12 medium, and Dulbecco's modified Eagle's medium (DMEM) were purchased from Thermo Fisher Scientific. CCK8was purchased from Sigma-Aldrich. PI and DAPI were purchased from Thermo Fisher Scientific. ROS and $\Delta \psi_{\mathrm{m}}$ assay kits were purchased from Sigma-Aldrich. Antibodies were purchased from Cell Signaling Technology.
Formononetin was purchased from SigmaAldrich. Formononetin was prepared as a 200 $\mathrm{mM}$ stock solution in sterile DMSO.

\section{Cell culture}

SW1463 cells were maintained in Leibovitz's 15 medium supplemented with $10 \% \mathrm{FBS}, 50 \mathrm{U} / \mathrm{mL}$ penicillin and $50 \mu \mathrm{g} / \mathrm{ml}$ streptomycin. T84 cells were cultured in a 1:1 mixture of Ham's F12 medium and DMEM supplemented with $10 \%$ FBS, $50 \mathrm{U} / \mathrm{ml}$ penicillin and $50 \mu \mathrm{g} / \mathrm{ml}$ streptomycin, and $2 \mathrm{mM}$ glutamine. HIEC- 6 cells were cultured in DMEM supplemented with $10 \%$ FBS, $50 \mathrm{U} / \mathrm{ml}$ penicillin, $50 \mu \mathrm{g} / \mathrm{ml}$ streptomycin, 4 $\mathrm{mM}$ glutamine and $20 \mathrm{mM}$ HEPES ( $\mathrm{pH} 7.5$ ).

\section{CCK-8 assay}

Cell suspensions $\left(8 \times 10^{4} \mathrm{cells} / \mathrm{ml}\right)$ were treated with vehicle (DMSO) or different doses of formononetin prior to seeding in a 96-well plate (100 $\mu \mathrm{l}$ total volume/well) and incubated at $37^{\circ} \mathrm{C}$ for $24 \mathrm{~h}$. Subsequently, $10 \mu \mathrm{l} /$ well of the CCK-8 solution was added and incubated at $37^{\circ} \mathrm{C}$ for 4 h. Optical density was measured at a wavelength of $450 \mathrm{~nm}$.

\section{Nuclear staining}

Cells were diluted with rich culture medium as described in "Cell culture" to a density of $8 \times 10^{4}$ cells $/ \mathrm{ml}$, and treated with equivalent vehicle or $100 \mu \mathrm{M}$ formononetin in a 24-well plate. The plate was incubated at $37{ }^{\circ} \mathrm{C}$ for $24 \mathrm{~h}$. The culture medium was gently removed, and the cells were gently washed twice with phosphatebuffered saline (PBS). $0.2 \mathrm{ml}$ of prepared staining solution containing $\mathrm{PI}$ and DAPI were added to the cells, and incubated at $37^{\circ} \mathrm{C}$ for 30 min. The solution was gently removed, and the plate was washed once with PBS. Fluorescent images were obtained by fluorescence microscopy at wavelengths of excitation/emission of 493/636 nm (PI) and 358/461 nm (DAPI). The intensity of the fluorescence was analysed with ImageJ software, and the percentage of apoptotic cells was expressed as the ratio of the PI fluorescence to DAPI fluorescence.

\section{Scratch wound healing assay}

Cell suspension $\left(8 \times 10^{4}\right.$ cells $\left./ \mathrm{ml}\right)$ was plated in a 12-well plate and cultured at $37{ }^{\circ} \mathrm{C}$ for $24 \mathrm{~h}$ to reach $80 \%$ confluence. A sterile $10-\mu \mathrm{L}$ pipette tip was used to generate a linear gap line and washed twice with PBS to remove the detached cells. The cells were fed fresh rich culture medium supplemented with equivalent vehicle (DMSO) or $100 \mu \mathrm{M}$ formononetin, and incubated 
at $37{ }^{\circ} \mathrm{C}$ overnight $(12 \mathrm{~h})$. Photography were taken under an inverted microscope.

\section{Cell invasion assay}

Cells were incubated with equivalent vehicle (DMSO) or $100 \mu \mathrm{M}$ formononetin for $24 \mathrm{~h}$ at $37^{\circ} \mathrm{C}$. Cells were then detached with trypsin and suspended in serum-free culture medium to a density of $8 \times 10^{4}$ cells $/ \mathrm{ml}$. The cells were then seeded into the matrigel-coated upper chamber of a boyden migration chamber. Rich culture medium was added to the lower chamber. Cells were incubated at $37^{\circ} \mathrm{C}$ for $6 \mathrm{~h}$. The upper chamber was gently removed and photography of the cells in the lower chamber were taken under light microscopy.

\section{Intracellular ROS assay}

Cell suspensions $\left(8 \times 10^{4}\right.$ cells $\left./ \mathrm{ml}\right)$ were supplemented with equivalent vehicle (DMSO) or $100 \mu \mathrm{M}$ formononetin were seeded in a 96-well plate, and incubated at $37^{\circ} \mathrm{C}$ for $3 \mathrm{~h}, 6 \mathrm{~h}, 12 \mathrm{~h}$, or $24 \mathrm{~h}$. The medium was removed, and washed with $100 \mu \mathrm{l} /$ well ROS assay buffer. $100 \mu \mathrm{l} /$ well of $1 \times$ ROS label (diluted in ROS assay buffer) was added and incubated at $37^{\circ} \mathrm{C}$ for $45 \mathrm{~min}$. The ROS label was gently removed, and $100 \mu \mathrm{l} /$ well ROS assay buffer in the kit was added. Fluorescence levels were measured with a microplate reader at an excitation (Ex)/emission (Em) ratio of $495 / 529 \mathrm{~nm}$.

\section{Mitochondrial $\Delta \Psi_{\mathrm{m}}$ assay}

Cell suspensions $\left(8 \times 10^{4}\right.$ cells $\left./ \mathrm{ml}\right)$ were seeded in a 96-well plate and incubated with equivalent vehicle (DMSO) or $100 \mu \mathrm{M}$ formononetin at 37 ${ }^{\circ} \mathrm{C}$ for $3,6,12$, or $24 \mathrm{~h}$. Ten microliters each well of JC-1 staining solution was added, and incubated for at $37^{\circ} \mathrm{C} 30 \mathrm{~min}$. The solution was carefully removed after a centrifugation at $400 \times$ $g$ for $5 \mathrm{~min}$, and washed twice with $200 \mu \mathrm{l} /$ well assay buffer. After the addition of $200 \mu \mathrm{L}$ assay buffer per well, fluorescence levels were measured with a microplate reader at $590 \mathrm{~nm}$.

\section{Western blot}

Cells $\left(8 \times 10^{4}\right.$ cells $\left./ \mathrm{ml}\right)$ were treated with the various doses of formononetin for $24 \mathrm{~h}$. The cells were collected by scratching and washed twice with PBS. Radio immunoprecipitation assay buffer (RIPA buffer) supplemented with protease and phosphatase inhibitors was used to lyse the cells and aid in protein extraction. BCA assay was used for the quantification of protein concentrations. Equivalent amounts of proteins were separated with SDS-PAGE and transferred to PVDF membranes. 5\% (w/v) dry milk or bovine serum albumin (BSA) was used to block the membranes at room temperature for $1 \mathrm{~h}$, and then incubated with primary antibodies at $4{ }^{\circ} \mathrm{C}$ overnight. The membranes were then washed with $1 \times$ TBST three times for $10 \mathrm{~min}$ each time. The membranes were then incubated with an Horse radish peroxidase (HRP)-conjugated secondary antibody at room temperature for $1 \mathrm{~h}$. The membranes were washed with $1 \times$ TBST three times for 10 min each time. Protein bands were detected by enhanced chemiluminescence. GAPDH served as the internal control for protein quantitation.

\section{Statistical analysis}

All data are expressed as mean \pm standard deviation (SD) of at least three independent experiments. Student's $t$ test or one-way ANOVA was used for statistical analysis. In all cases, $p<$ 0.05 was considered statistically significant.

\section{RESULTS}

\section{Inhibition of cell proliferation by formononetin}

To determine the effect of formononetin on CRC cell proliferation, cells were incubated with the indicated doses of formononetin for $24 \mathrm{~h}$. Formononetin began to show significant inhibitory effects on human CRC SW1463 cell growth at a concentration of $20 \mu \mathrm{M}$. Formononetin exhibited dose-dependent inhibitory effects on SW1463 cells: (Figure 1 A). Similar results were observed in T84 cells (Figure $1 \mathrm{~B}$ ). The proliferation of normal HIEC-6 cells was unaffected by formononetin (Figure 1 C).

A

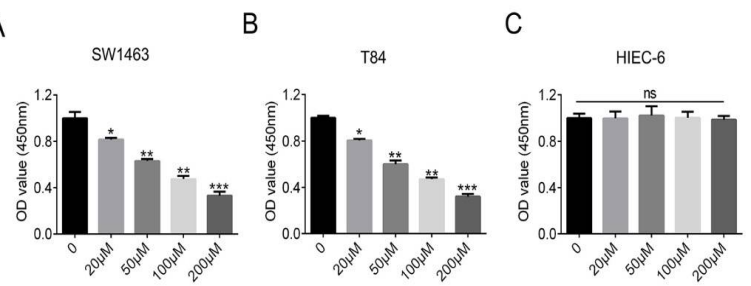

Figure 1: Inhibition of cell proliferation by formononetin. A-C, $O D_{450}$ values represent the viability of SW1463, T84, and HIEC-6 cells, respectively, treated with the indicated concentrations of formononetin. Results are expressed as mean \pm SD of at least three independent experiments $\left(^{*} p<0.05\right.$ vs vehicle (DMSO, $0 \mu \mathrm{M}),{ }^{\star *} p<0.01$ vs vehicle, ${ }^{* * *} p<$ 0.001 vs vehicle) 


\section{Induction of apoptosis by formononetin}

Apoptotic cells were stained with $\mathrm{PI}$ and monitored by DAPI staining. The percentage of apoptotic SW1463 cells treated with $100 \mu \mathrm{M}$ formononetin for $24 \mathrm{~h}$ was more than four times higher than the percentage of cells treated with equivalent vehicle (Figure 2 A). The percentage of apoptotic T84 cells treated with formononetin was nearly triple the percentage of cells treated with equivalent vehicle (Figure $2 \mathrm{~B}$ ), whereas HIEC-6 cells were unaffected by treatment with formononetin (Figure $2 \mathrm{~B}$ ).

A

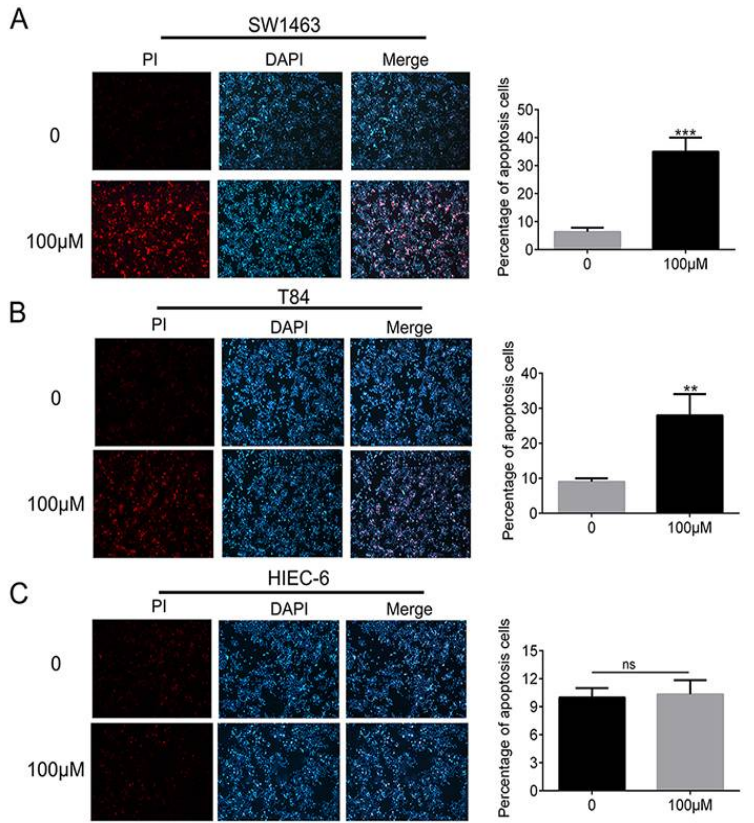

Figure 2: Induction of apoptosis by formononetin. AC. The population of apoptotic SW1463, T84, and HIEC-6 cells treated with equivalent vehicle or $100 \mu \mathrm{M}$ formononetin, respectively. Left, images of cells stained with PI and DAPI. Right, Percent apoptotic cells (ratio of PI fluorescence to DAPI fluorescence, $100 \%)$. Results are expressed as mean \pm SD ( $\mathrm{n}=$ 3) $\left({ }^{* *} p<0.01\right.$ vs vehicle, ${ }^{* *} p<0.001$ vs vehicle)

\section{Suppression of cell migration and invasion by formononetin}

The effect of formononetin on cell migration and invasion was tested using the scratch wound healing and invasion assays, respectively. The SW1463 cells (Figure 3 A) and T84 cells (Figure 3 B) that were treated with vehicle only were able to migrate into the denuded zone and invade the lower chamber of a Boyden migration chamber. However, after the treatment with $100 \mu \mathrm{M}$ formononetin for $24 \mathrm{~h}$, cell migration and invasion were suppressed in both cell types (Figure 3).
A

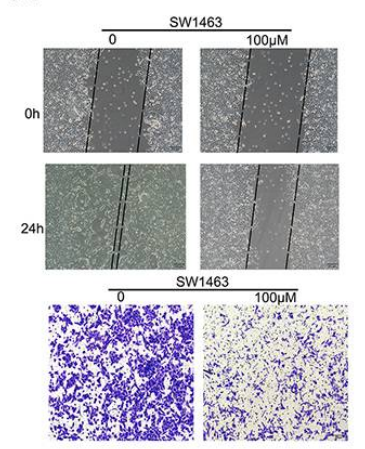

B

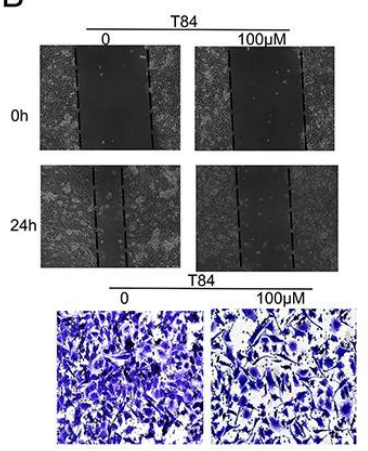

Figure 3: Suppression of cell migration and invasion by formononetin in SW1463 and T84 cells. A Scratch wound healing assay. B: Cell invasion assay. Figures are representative of at least three independent experiments

\section{Effect of formononetin on mitochondrial ROS levels and $\Delta \boldsymbol{\Psi}_{\mathrm{m}}$}

To investigate whether mitochondria are involved in the anticancer effects elicited by formononetin, intracellular ROS levels and mitochondrial $\Delta \psi_{\mathrm{m}}$ were measured at different time points. Formononetin, at a concentration of $100 \mu \mathrm{M}$, induced mitochondrial ROS generation in a timedependent manner. At $3 \mathrm{~h}, 100 \mu \mathrm{M}$ formononetin did not cause significant intracellular ROS generation, whereas at $6 \mathrm{~h}$, ROS levels in both SW1463 cells and T84 cells treated with $100 \mu \mathrm{M}$ formononetin were 2.5 times higher than ROS levels measured in vehicle-treated cells.

Formononetin did not elicit any effects on the intracellular ROS levels in normal HIEC-6 cells (Figure $4 \mathrm{~A})$. Formononetin $(100 \mu \mathrm{M})$ depolarized mitochondria in a time-dependent manner, with a significant decrease in mitochondrial $\Delta \psi_{\mathrm{m}}$ at $6 \mathrm{~h}$, but not at $3 \mathrm{~h}$, in both SW1463 cells and T84 cells. Intracellular ROS levels and mitochondrial $\Delta \psi_{\mathrm{m}}$ were unaffected by formononetin treatment in HIEC-6 cells (Figure 4). These results indicate that mitochondria-dependent pathway(s) could contribute to the proapoptotic effects of formononetin.

\section{Inhibition of MMP-2 and MMP-9 expression}

Matrix metalloproteinases (MMPs) are essential enzymes in cancer cell invasion, and MMP-2 and MMP-9 are significantly elevated in CRC. Thus, the effects of various concentrations of formononetin on the expression levels of MMP-2 and MMP-9 were examined by immunoblotting. The expression levels of MMP-2 and MMP-9 was inhibited by formononetin in a dose-dependent manner in both SW1463 and T84 cells (Figure $5)$. These data indicate that the suppressive effects of formononetin on CRC cell invasion are 
regulated by the inhibition of MMP2 and MMP9 expression.

A

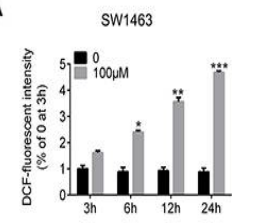

B

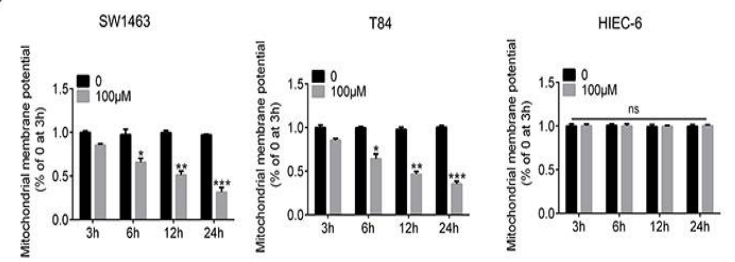

Figure 4: Effects on mitochondrial ROS levels and $\Delta \psi_{\mathrm{m}}$ by formononetin in SW1463, T84, and HIEC-6 cells. A; ROS generation at different time points with or without formononetin. B; Mitochondrial $\Delta \psi_{\mathrm{m}}$ values at different time points with or without formononetin. Results are expressed as mean $\pm \mathrm{SD}(\mathrm{n}=3)$; $p<$ $0.05,{ }^{* *} p<0.01, \quad p<0.001$, compared with vehicle
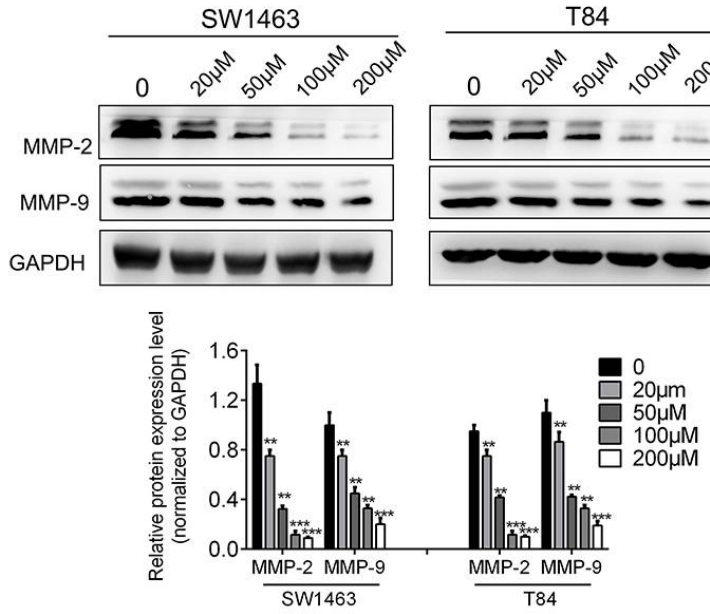

Figure 5: Inhibition of MMP-2 and MMP-9 expression by formononetin in SW1463 and T84 cells. Upper, representative immunoblotting images of MMP-2, MMP-9, and GAPDH expression. Lower, relative protein expression levels of MMP-2 and MMP-9 normalized to GAPDH. Densities of protein bands were quantified using ImageJ software. Results are expressed as the mean $\pm \mathrm{SD}(\mathrm{n}=3) ;{ }^{* *} p<0.01,{ }^{* \star *} p<$ 0.001 , compared with vehicle

Effect of formononetin on apoptosis- and proliferation-associated protein expressions

The expression levels of apoptosis- and proliferation-associated proteins were assessed by western blot analysis. The levels of the antiapoptotic protein Bcl-2 were significantly suppressed by formononetin, whereas formononetin increased the levels of proapoptotic proteins Bax, caspase-9, and cytochrome C. Formononetin also inhibited the expressions of proliferation -associated proteins, such as c-Myc, cyclin E, and CDK2. The effects of formononetin on these proteins were dose-dependent in both SW1463 and T84 cells (Figure 6). These results indicate that formononetin inhibits proliferation and promotes apoptosis in human CRC cells by regulating the expressions of apoptosis-related proteins (such as Bcl-2, Bax, caspase-9, and cytochrome $c$ ) and proliferation-associated proteins (such asc-Myc, cyclin E, and CDK2).
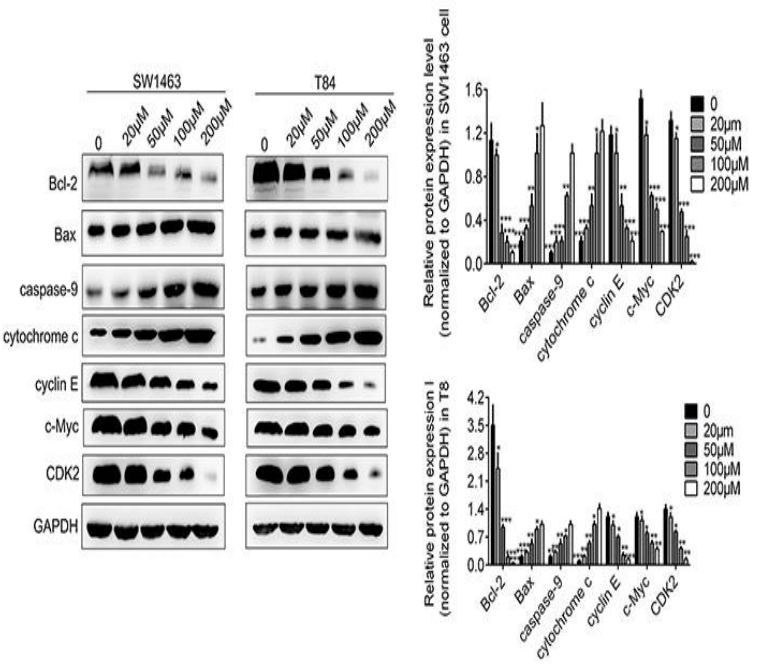

Figure 6: Effect of formononetin on the expression of apoptosis- and proliferation -associated proteins in SW1463 and T84 cells. Left, representative immunoblotting images of Bcl-2, Bax, caspase-9, cytochrome c,c-Myc, cyclin E, CDK2, and GAPDH. Right, relative protein expression levels of indicated proteins normalized to GAPDH. Densities of protein bands were quantified using ImageJ software. Results are expressed as mean $\pm \mathrm{SD}(\mathrm{n}=3) ;{ }^{\star} p<0.05,{ }^{* *} p<$ $0.01,{ }^{\star \star x} p<0.001$, compared with vehicle

\section{Induction of apoptosis by formononetin via mitochondria-dependent MAPK pathway}

Formononetin treatment enhanced the generation of mitochondrial ROS and collapse of $\Delta \psi_{\mathrm{m}}$ (Figure 4). Next the possible role of the MAPK pathway was tested after formononetin treatment [9]. Formononetin significantly suppressed the phosphorylation of ERK1/2 and promoted the phosphorylation of c-Jun Nterminal kinase (JNK) and p38 in a dosedependent manner in both SW1463 and T84 cells (Figure 7). These results suggest that formononetin induces human $\mathrm{CRC}$ cell apoptosis by restraining the phosphorylation of ERK1/2 and activating the phosphorylation of JNK and p38 via the mitochondria-dependent MAPK pathway. 


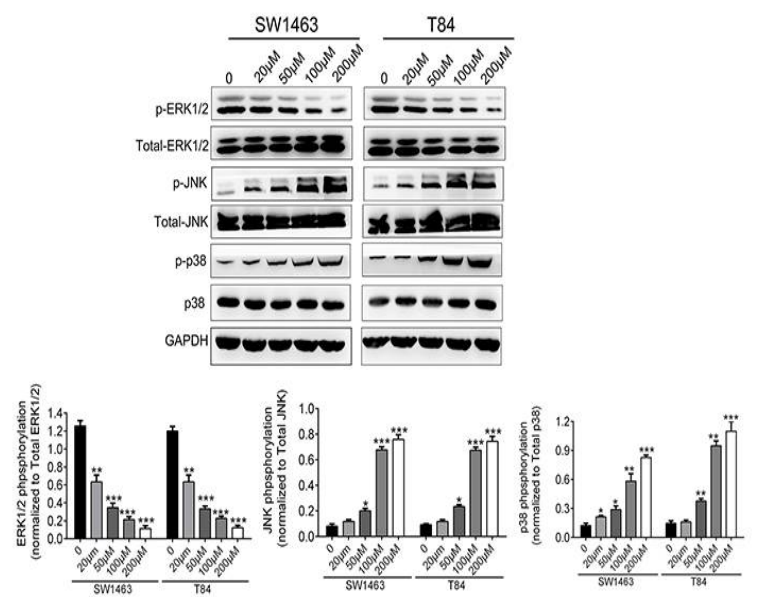

Figure 7: The induction of cell apoptosis by formononetin involving the mitochondria-dependent MAPK pathway in SW1463 and T84 cells. Upper, Representative immunoblotting images of ERK1/2, pERK1/2, JNK, p-JNK, p38, p-p38, and GAPDH. Lower, relative protein expression levels of indicated proteins normalized to GAPDH. Densities of protein bands were quantified using ImageJ software. Results are expressed as mean $\pm \mathrm{SD}(\mathrm{n}=3) ;{ }^{*} p<0.05,{ }^{* *} p<0.01$, $p<0.001$, compared with vehicle

\section{DISCUSSION}

The present work reports that formononetin exhibited antiproliferative and apoptotic effects on human CRC SW1463 cells and T84 cells in a dose-dependent manner, without causing HIEC6 cytotoxicity. Moreover, this study showed for the first time that formononetin enhanced cell apoptosis in SW1463 and T84 cells involving the mitochondria-dependent MAPK pathway.

MAPKs, also known as extracellular signalregulated kinases (ERKs), are highly conserved molecules regulating various extracellular and intracellular signalling pathways[9]. Three subfamilies of MAPK including ERK1/2, JNK, and p38 kinase are associated with the regulation of many physiopathological processes, such as apoptosis, differentiation, and senescence [9].

ROS acts as a common and important modulator of many cellular signalling pathways. It is known to activate several MAPKs, which can thus induce apoptosis in response to cellular oxidative stress [9]. Mitochondria are the main sources of ROS, generated specifically by complexes I and III of the respiratory chain. Increased cellular oxidative stress may trigger the opening of the mitochondrial mega channel, known as the mitochondrial permeability transition pore, which causes mitochondrial dysfunction, depolarization, rupture of the outer membrane, and release of proapoptotic proteins like cytochrome $c$, resulting in cell death [10]. However, whether formononetin can elicit anticancer effects in CRC via the mitochondria-dependent MAPK pathway has not been investigated previously.

This study showed that in human CRC SW1463 and T84 cells, formononetin treatment significantly increased the expression of proapoptotic proteins, decreased the expression of proliferation-associated proteins, and exhibited strong antiproliferative and apoptotic effects in a dose-dependent manner, without any HIEC-6 cytotoxicity. Formononetin suppressed the expression of MMP-2 and MMP-9, thus inhibited cell migration and invasion. Remarkably, formononetin caused mitochondrial depolarization and promoted ROS generation in a time-dependent manner. ROS acted on the upstream of MAPK then significantly decreased the phosphorylation of ERK $1 / 2$ and increased the phosphorylation of JNK and p38, leading to the activation of these MAPKs.

\section{CONCLUSION}

The findings of the present work demonstrate that formononetin inhibits human CRC cell proliferation and invasion in vitro while it does not influence normal cell growth. Formononetin induces cell apoptosis involving the mitochondria-dependent MAPK pathway. This study provides in vitro information that formononetin exhibits antitumor activity in CRC cells for in vivo studies and for the further clinical trials.

\section{DECLARATIONS}

\section{Acknowledgement}

This work was funded as part of Natural Science Foundation of China titled 'Research on potential cancer risk mechanism and avoidance strategy of rhubarb' (grant no. 81673795); and part of Jiangsu Natural Science Foundation Project titled 'To explore the mechanism and avoidance strategy of rhubarb carcinogenic risk based on intestinal flora' (grant no. BK20151567).

\section{Disclosure of interest}

The authors declare that there is no conflict of interest associated with this work.

\section{Contribution of authors}

We declare that this work was done by the authors named in this article and all liabilities pertaining to claims relating to the content of this article will be borne by the authors. Xiao-hong 
Wang and Zhi-guang Sun designed all the experiments and revised the paper. Lei Luo and Li-na Liu performed the experiments, Jing Yan and Li Xuan wrote the paper and final approval.

\section{REFERENCES}

1. Bodalal Z, Bendardaf R. Colorectal carcinoma in a Southern Mediterranean country: The Libyan scenario. World J Gastrointest Oncol 2014; 6(4): 98-103.

2. De Rosa M, Pace U, Rega D, Costabile V, Duraturo F, Izzo P, Delrio P. Genetics, diagnosis and management of colorectal cancer (Review). Oncol Rep 2015; 34(3): 1087-1096.

3. Marin JJ, Sanchez de Medina F, Castano B, Bujanda L, Romero MR, Martinez-Augustin O, Moral-Avila RD, Briz O. Chemoprevention, chemotherapy, and chemoresistance in colorectal cancer. Drug Metab Rev 2012; 44(2): 148-172.

4. Jin $M$, Zhao $K$, Huang $Q$, Shang $P$. Structural features and biological activities of the polysaccharides from Astragalus membranaceus. Int J Biol Macromol 2014; 64(257-266.

5. Chen J, Zeng J, Xin M, Huang W, Chen X. Formononetin induces cell cycle arrest of human breast cancer cells via IGF1/PI3K/Akt pathways in vitro and in vivo. Horm Metab Res 2011; 43(10): 681-686.

6. Zhou $R$, Xu L, Ye $M$, Liao $M$, Du $H$, Chen $H$. Formononetin inhibits migration and invasion of MDAMB-231 and 4T1 breast cancer cells by suppressing MMP-2 and MMP-9 through PI3K/AKT signaling pathways. Horm Metab Res 2014; 46(11): 753-760.

7. Li T, Zhao $X$, Mo Z, Huang $W$, Yan $H$, Ling Z, Ye $Y$. Formononetin promotes cell cycle arrest via downregulation of Akt/Cyclin D1/CDK4 in human prostate cancer cells. Cell Physiol Biochem 2014; 34(4): 1351-1358.

8. Ye Y, Hou R, Chen J, Mo L, Zhang J, Huang Y, Mo Z. Formononetin-induced apoptosis of human prostate cancer cells through ERK1/2 mitogen-activated protein kinase inactivation. Horm Metab Res 2012; 44(4): 263267.

9. Chatterjee $N$, Das $S$, Bose D, Banerjee $S$, Jha $T$, Das Saha $K$. Lipid from infective $L$. donovani regulates acute myeloid cell growth via mitochondria dependent MAPK pathway. PLoS One 2015; 10(3): e0120509.

10. Setia S, Nehru B, Sanyal SN. Upregulation of MAPK/Erk and PIJK/Akt pathways in ulcerative colitis-associated colon cancer. Biomed Pharmacother 2014; 68(8): 10231029.

11. Mendoza MC, Er EE, Blenis J. The Ras-ERK and PI3KmTOR pathways: cross-talk and compensation. Trends Biochem Sci 2011; 36(6): 320-328.

12. Zhou JX, Fan LX, Li X, Calvet JP, Li X. TNFalpha signaling regulates cystic epithelial cell proliferation through Akt/mTOR and ERK/MAPK/Cdk2 mediated Id2 signaling. PLoS One 2015; 10(6): e0131043.

13. Yuan L, Wang J, Xiao H, Wu W, Wang Y, Liu X. MAPK signaling pathways regulate mitochondrial-mediated apoptosis induced by isoorientin in human hepatoblastoma cancer cells. Food Chem Toxicol 2013; 53: 62-68.

14. Streuli I, Santulli $P$, Chouzenoux S, Chapron C, Batteux F. Activation of the MAPK/ERK Cell-Signaling Pathway in Uterine Smooth Muscle Cells of Women With Adenomyosis. Reprod Sci 2015; 22(12): 1549-1560.

15. Jalmi SK, Sinha AK. ROS mediated MAPK signaling in abiotic and biotic stress- striking similarities and differences. Front Plant Sci 2015; 6: 769-778.

16. Wang J, Du H, Nie $Y$, Wang $Y$, Dai $H$, Wang $M$, Wang $D$, $\mathrm{Xu}$ A. Mitochondria and MAPK cascades modulate endosulfan-induced germline apoptosis in Caenorhabditis elegans. Toxicol Res (Camb) 2017; 6(4): 412-419.

17. Shi L, Qin $H$, Jin X, Yang X, Lu X, Wang $H$, Wang $R$, Yu $D$, Feng $B$. The natural phenolic peperobtusin $A$ induces apoptosis of lymphoma U937 cells via the Caspase dependent and p38 MAPK signaling pathways. Biomed Pharmacother 2018; 102: 772-781.

18. Giorgio V, Guo L, Bassot C, Petronilli V, Bernardi $P$. Calcium and regulation of the mitochondrial permeability transition. Cell Calcium 2018; 70: 56-63. 